\title{
Development of an Automated Drug Delivery System for an Ultra-Short-acting $\beta$-Blocker, Landiolol, to Stably Reduce Myocardial Oxygen Consumption without Inducing Circulatory Collapse in a Canine Heart Failure Model
}

Takuya Nishikawa ( $\nabla$ nishikawa.takuya75@ncvc.go.jp)

National Cerebral and Cardiovascular Center https://orcid.org/0000-0002-4951-7831

Kazunori Uemura

Department of Cardiovascular Dynamics, National Cerebral and Cardiovascular Center

\section{Yohsuke Hayama}

Department of Cardiovascular Dynamics, National Cerebral and Cardiovascular Center

\section{Toru Kawada}

Department of Cardiovascular Dynamics, National Cerebral and Cardiovascular Center

\section{Keita Saku}

Department of Cardiovascular Dynamics, National Cerebral and Cardiovascular Center Masaru Sugimachi

Department of Cardiovascular Dynamics, National Cerebral and Cardiovascular Center

\section{Research}

Keywords: $\beta$-blocker, automated drug delivery, closed-loop control, haemodynamics

Posted Date: August 5th, 2020

DOI: https://doi.org/10.21203/rs.3.rs-52352/v1

License: (c) (i) This work is licensed under a Creative Commons Attribution 4.0 International License. Read Full License 


\section{Abstract}

Background: Beta-blockers are well known to reduce myocardial oxygen consumption $\left(\mathrm{MVO}_{2}\right)$ and improve the prognosis of heart failure (HF) patients. Although the use of $\beta$-blockers in the acute phase of $\mathrm{HF}$ can be expected to be beneficial, the negative chronotropic and inotropic effects limit their use due to the risk of circulatory collapse (cardiogenic shock, and/or pulmonary congestion). A safe method to administer $\beta$-blockers in the acute phase of HF is in great need. In this study, we developed an automated drug delivery system that controls the infusion of landiolol, an ultra-short-acting $\beta$-blocker, while preventing circulatory collapse.

Method: We designed a system that simultaneously regulates cardiac function and volume status to control haemodynamics. The system monitors arterial pressure (AP), left atrial pressure $\left(P_{L A}\right)$, right atrial pressure, and cardiac output. Using negative feedback of haemodynamics, the system controls mean AP and mean $P_{L A}$ by administering landiolol, dextran, and furosemide. We applied the system for 60 min to 5 mongrel dogs with rapid pacing-induced $\mathrm{HF}$, and assessed haemodynamics, $\mathrm{MVO}_{2}$ and lactate.

Results: In all dogs, the system successfully adjusted delivery of the drugs resulting in accurate control of mean AP and mean $P_{\text {LA. F }}$. From 15 to 60 min after the system was activated, median of absolute performance error (index of precision of control) was small for mean AP (median [interquartile range], 2.5 [2.1 - 3.7] \%) and mean $\mathrm{P}_{\mathrm{LA}}(4.1[1.8$ - 6.2] \%). Although the system decreased mean AP compared to baseline, mean and systolic AP were maintained not lower than 70 and $100 \mathrm{mmHg}$, respectively, and lactate did not increase. Furthermore, the system significantly decreased $\mathrm{P}_{\mathrm{LA}}$ and $\mathrm{MVO}_{2}$ (3.6 [3.3 - 4.0] to $2.7[2.5-3.3] \mathrm{ml} \cdot \mathrm{min}^{-1} \cdot 100 \mathrm{~g}$ left ventricular weight ${ }^{-1}$ ) compared to baseline. Consequently, the automated drug delivery system successfully reduced $\mathrm{MVO}_{2}$ without inducing circulatory collapse.

Conclusion: We developed an automated landiolol delivery system that achieved safe administration of landiolol in a canine model of acute HF. The system controlled AP and $\mathrm{P}_{\mathrm{LA}}$ accurately and stably, and reduced $\mathrm{MVO}_{2}$. With further development for clinical application, the automated drug delivery system may be the key tool to improve management of patients with HF.

\section{Introduction}

Beta-blockers are drugs that bind to beta-adrenergic receptors and inhibit the binding of norepinephrine and epinephrine [1]. This inhibition reduces the cardiac workload and myocardial oxygen consumption $\left(\mathrm{MVO}_{2}\right)$ through negative chronotropic and inotropic effects [2,3]. This is the key mechanism of cardioprotection by $\beta$-blockers. Other mechanisms of cardioprotection by $\beta$-blockers include the suppression of renin release [4], reduction of myocardial oxygen stress [5], and normalisation of calcium handling in the sarcoplasmic reticulum [6].

In the chronic phase, it is well known that $\beta$-blockers reduce cardiac remodelling and improve the prognosis of heart failure patients with preserved ejection fraction $[7,8]$. In the acute phase, perioperative 
stress increases norepinephrine and epinephrine spillover [9] causing tachycardia and hypertension, and increases $\mathrm{MVO}_{2}$ [10]. Excessive $\mathrm{MVO}_{2}$ leads to myocardial ischemia. The European guideline recommends using $\beta$-blockers in the perioperative phase of cardiac surgery [11]. In addition, withdrawal of $\beta$-blockers in the acute phase of acute decompensated HF worsens the prognosis [12]. These studies indicate the benefit of $\beta$-blockers in acute phase. However, in patients with impaired cardiac function, the negative inotropic and chronotropic effects of $\beta$-blockers may lead to circulatory collapse, i.e., cardiogenic shock or pulmonary congestion $[13,14]$. This risk of circulatory collapse hampers the initiation of $\beta$ blockers in high-risk patients. A method of regulating $\beta$-blockers without inducing circulatory collapse is essential for safe perioperative management and for patients with impaired cardiac function. Therefore, we aimed to develop an automated $\beta$-blocker administration system that controls the dose of $\beta$-blocker appropriately using negative feedback of haemodynamics in individual patients.

We previously developed automated cardiovascular drug delivery systems that administered inotropic agents, vasodilators, diuretics, and/or infused fluids to simultaneously control arterial pressure (AP), cardiac output (CO), and left atrial pressure ( $\left.P_{L A}\right)$ under acute heart failure (HF) condition [15-17]. We hypothesize that by allowing a mild drop of AP to an acceptable range, we can extend the system to infuse $\beta$-blockers. Jannet et al. [18] reported an automated drug delivery system for $\beta$-blockers, which controlled heart rate (HR) by administering esmolol, a short-acting $\beta$-blocker. However, since they focused on HR only, the risk of esmolol-induced circulatory collapse remained unsolved.

With the above background, we aimed to develop an automated $\beta$-blocker administration system that reduces $\mathrm{MVO}_{2}$ without the risk of circulatory collapse. In a canine model of rapid pacing-induced $\mathrm{HF}$, we evaluated the performance of the system that controls the infusion of landiolol, an ultra-short-acting $\beta$ blocker.

\section{Methods}

\section{Automated drug delivery system}

In this study, by extending the systems that we reported previously [15-17], we developed an automated drug delivery system to control the infusion rates of landiolol and dextran, and the injection of furosemide to reduce $\mathrm{MVO}_{2}$ without inducing circulatory collapse in subjects with acute HF. Figure 1 shows the scheme of our system. The details of the system are described in Supplemental Material. In brief, the user sets the target values of mean $A P\left(A P^{*}\right)$ and mean $P_{L A}\left(P_{L A}{ }^{*}\right)$. The system measures $A P, C O, P_{L A}$ and right atrial pressure $\left(P_{R A}\right)$, and then low-pass filtered these hemodynamic variables at a cut-off frequency of $0.1 \mathrm{~Hz}$ to calculate mean values to be used in the closed-loop feedback system. From the measured hemodynamic variables, the system calculates the slope of the Frank-Starling curve for left $\left(\mathrm{S}_{\mathrm{L}}\right)$ and right $\left(S_{R}\right)$ ventricles, systemic vascular resistance $(R)$ and stressed blood volume $(V)$. From $A P^{\star}$ and $P_{L A}$ * and the measured hemodynamic data, the system determines the target values of $S_{L}\left(S_{L^{*}}{ }^{*}\right.$ and $V\left(V^{*}\right)$. To minimise the difference between $S_{L}{ }^{*}$ and $S_{L}$, a proportional-integral feedback controller adjusts the 
infusion rate of landiolol. To minimise the difference between $\mathrm{V} *$ and $\mathrm{V}$, a nonlinear feedback controller adjusts the infusion rate of dextran or the injection of furosemide. Using these feedback controllers, the system administers landiolol and dextran or furosemide to bring mean AP and mean $\mathrm{P}_{\mathrm{LA}}$ to the preset target values.

\section{Animal experiments}

\section{Rapid pacing-induced heart failure model}

We used five adult mongrel dogs weighing $21.0-29.5 \mathrm{~kg}$ (male/female, 4/1). We induced anaesthesia with intravenous thiamylal sodium $\left(25 \mathrm{mg} \cdot \mathrm{kg}^{-1}\right)$, performed endotracheal intubation, and maintained an appropriate anaesthesia level during the experiment by continuous inhalation of isoflurane (1-2\%). Body temperature was maintained between 37 and $38^{\circ} \mathrm{C}$. We performed transthoracic echocardiography to measure left ventricular end-diastolic dimension (LVDD), left ventricular end-systolic dimension (LVDS) and ejection fraction under normal conditions. After inserting a bipolar pacing lead (Model BT-60P, Star Medical Inc., Tokyo, Japan) to the right ventricular apex through the right jugular vein, we connected a generator (Model SIP-501, Star Medical, Tokyo, Japan) to the pacing lead and implanted it in a subcutaneous pocket at the neck [16]. We closed the incisions and withdrew anaesthesia. One day after implantation, we started rapid ventricular pacing at a rate of 230 beats $\cdot \mathrm{min}^{-1}$ and continued for three weeks to induce HF.

\section{Experimental preparation and automated drug control}

We performed experiments the day after discontinuing rapid pacing. Under anaesthesia induced as described above, we performed transthoracic echocardiography to assess LVDS, LVDD and ejection fraction, and recorded an electrocardiogram (ECG) to calculate HR. We placed 8-Fr sheath introducers in the right femoral artery to measure AP, and in the right and left femoral veins for infusing dextran and landiolol, respectively, and placed a 10-Fr sheath introducer in the right jugular vein to measure $\mathrm{P}_{\mathrm{RA}}$. We inserted a catheter to the coronary sinus via the right jugular vein under fluoroscopy. After a left thoracotomy and pericardial incision, we introduced a catheter into the left atrial appendage to measure $P_{\text {LA }}$. We placed ultrasonic flow probes at the ascending aorta (20PS; Transonic, Ithaca, NY) and the left circumflex artery (2.5PS; Transonic, Ithaca, NY) to measure CO and coronary flow, respectively.

We attached an infusion pump (CFV-3200, Nihon Kohden, Tokyo, Japan) for administering landiolol, and a roller pump (Minipulse 3, Gilson, Middleton, $\mathrm{WI}$ ) for administering dextran. We controlled these pumps via a laboratory computer (LC-72N10, Logitec, Tokyo, Japan). We used the sheath introducer at the femoral vein for injecting furosemide according to a command signal from the computer. We digitised all hemodynamic data at $200 \mathrm{~Hz}$ with an analogue-to-digital converter (AD 12-16, Contec, Osaka, Japan) and stored the data in a dedicated laboratory computer system.

\section{Experimental Protocol}


After stabilisation for $30 \mathrm{~min}$, we connected the closed-loop system to the animal. We set AP* as 10 to 15 $\mathrm{mmHg}$ lower than baseline AP, but not lower than $70 \mathrm{mmHg}$. We set $P_{L A}{ }^{*}$ as baseline $P_{L A}$, but not higher than $18 \mathrm{mmHg}$. After activating the system by closing the feedback loops of drug administration (Fig. 1), we recorded the infusion rates of landiolol and dextran and the injection of furosemide on the computer. The performance of the system was monitored for $60 \mathrm{~min}$, and arterial and coronary sinus blood samples were collected simultaneously at baseline ( $0 \mathrm{~min}), 30$, and $60 \mathrm{~min}$ after system activation.

After completion of the protocol, the dogs were euthanized with an intravenous injection of pentobarbital and potassium chloride. We measured left ventricular weight after excision of the adjacent right ventricular muscle and valvular tissues.

\section{Myocardial oxygen consumption and blood gas analysis}

We measured oxygen contents of the arterial and coronary sinus blood samples using a co-oximeter (AVOXimeter 4000; Instrumentation Laboratory, Bedford, MA). According to Fick's principle, the product of coronary flow and the difference between arterial and coronary sinus oxygen contents yields $\mathrm{MVO}_{2}$. We normalized $\mathrm{MVO}_{2}$ by $100 \mathrm{~g}$ left ventricular weight (LVW). We also performed blood gas analysis of arterial blood samples using a blood gas analyser (ABL800 FLEX; Radiometer, Tokyo, Japan) to assess $\mathrm{pH}$, electrolytes, lactate, and partial pressure oxygen and carbon dioxide.

\section{Data analysis}

Efficacy of the automated drug delivery system.

To evaluate the precision and stability of the system, we calculated the performance error (PE), median PE (MDPE), median absolute PE (MDAPE), and wobble by the following equations [19].

$$
\begin{gathered}
\operatorname{PE}(\mathrm{t})=\frac{\operatorname{Variable}(\mathrm{t})-\operatorname{Target}(\mathrm{t})}{\operatorname{Variable}(\mathrm{t})} * 100 \\
\text { MDPE }=\operatorname{median}\{\operatorname{PE}(\mathrm{t})\} \\
\mathrm{MDAPE}=\operatorname{median}\{|\mathrm{PE}(\mathrm{t})|\}
\end{gathered}
$$

Wobble $=\operatorname{median}\{|\mathrm{PE}(\mathrm{t})-\mathrm{MDPE}|\}$

where $t$ represents a time unit. Divergence is the slope of the regression line between $|P E(t)|$ and $t(\mathrm{~min})$. MDPE, MDAPE, wobble, and divergence indicate the bias, accuracy, stability, and trend of the absolute error, respectively. Since haemodynamics was stabilised after approximately $15 \mathrm{~min}$, we calculated PE for $A P$ and $P_{L A}$ from 15 to 60 min after the system was activated.

\section{Statistics}


Data are expressed as median (interquartile range). We used Friedman's test followed by the post hoc Conover's test for multiple comparisons among different time point data. We performed all statistical analyses using R version 3.4.3 (R Foundation for Statistical Computing, Vienna, Austria). We considered differences to be significant at $p<0.05$.

\section{Result}

Rapid pacing-induced heart failure model

In all five dogs, rapid pacing increased LVDD and LVDS, and reduced ejection fraction to below $40 \%$ (Fig. 2). Mean $A P$ and mean $P_{L A}$ just before activation of the drug delivery system were $88(85-89) \mathrm{mmHg}$ and $18(15-20) \mathrm{mmHg}$, respectively. These data indicated that rapid pacing for three weeks induced HF reasonably well in the animals.

Hemodynamic control by the automated drug delivery system

Figure 3 shows the representative time series data of one dog during hemodynamic control by the system. After activation at $0 \mathrm{~min}$, the system started to control the infusion rates of landiolol and dextran, and injection of furosemide (Fig. $3 A$ ). As a result, the hemodynamic parameters $S_{L}$ and $V$ approached their respective target values (Fig. 3B). By controlling $S_{L}$ and V, mean AP and mean $P_{L A}$ reached the preset target values accurately (Fig. 3C). HR and coronary flow were reduced markedly within 20 min (Fig. 3D). From 15 to $60 \mathrm{~min}$ after the system activation, IPE| for mean AP or mean $P_{L A}$ was less than $10 \%$. These results indicated an acceptable accuracy of hemodynamic control by our system.

Figure 4 summarises the results of time series data of all five dogs. The solid line and the grey shade indicate median and interquartile range, respectively. Figure 4A shows the infusion rate of landiolol and cumulative doses of dextran and furosemide. The trend of landiolol infusion rate varied among the animals. In two dogs, the infusion rate of landiolol initially increased to above $8 \mu \mathrm{g} \cdot \mathrm{min}^{-1} \cdot \mathrm{kg}^{-1}$, then gradually decreased to nearly $0 \mu \mathrm{g} \cdot \mathrm{min}^{-1} \cdot \mathrm{kg}^{-1}$. In the other three dogs, the infusion rate of landiolol increased gradually over time during hemodynamic control. In all dogs, the infusion rate of landiolol averaged over the 60-min period was $18.7(8.9-39.4) \mu \mathrm{g} \cdot \mathrm{min}^{-1} \cdot \mathrm{kg}^{-1}$, and the cumulative dose of dextran was $3.7(3.6-4.4) \mathrm{ml}^{-\mathrm{kg}^{-1}}$. Furosemide was injected in three dogs, and the cumulative furosemide dose was $10(0-20) \mathrm{mg}$. Figure $4 B$ and $C$ demonstrate that our system accurately controlled $S_{L}, V, A P$, and $P_{L A}$. |PE| for mean AP or mean $P_{L A}$ was less than $10 \%$ from 15 to 60 min after system activation (Fig. 4D).

Figure 5 summarises the hemodynamic data and $\mathrm{MVO}_{2}$ at baseline $(0 \mathrm{~min}), 30$, and $60 \mathrm{~min}$ after system activation. At 60 min, mean, systolic and diastolic AP decreased significantly compared to baseline. However, in all dogs, the system maintained mean AP not lower than $70 \mathrm{mmHg}$, and systolic AP not lower than $100 \mathrm{mmHg}$ during the 60-min hemodynamic control period. Mean $\mathrm{P}_{\mathrm{LA}}$ observed at $60 \mathrm{~min}$ (17 [15$18] \mathrm{mmHg}$ ) was slightly but significantly lower compared to baseline $\left(18\right.$ [15 - 20] mmHg), whereas $P_{R A}$ remained unaltered. These results indicated that our system prevented cardiogenic shock and/or 
pulmonary congestion. $\mathrm{MVO}_{2}$ decreased by approximately $25 \%\left(2.7[2.5-3.3] \mathrm{ml} \cdot \mathrm{min}^{-1} \cdot 100 \mathrm{~g} \mathrm{LVW}^{-1}\right)$ at $60 \mathrm{~min}$ compared to baseline $\left(3.6[3.3-4.0] \mathrm{ml} \cdot \mathrm{min}^{-1} \cdot 100 \mathrm{~g} \mathrm{LVW}{ }^{-1}\right) . \mathrm{HR}, \mathrm{CO}$, and coronary flow at 30 and 60 min decreased significantly from baseline.

Accuracy of the automated system

Figure 6 shows the performance of the automated system in controlling mean AP and mean $\mathrm{P}_{\mathrm{LA}}$. The MDAPE (\%) for mean AP and mean $\mathrm{P}_{\mathrm{LA}}$ were $2.5(2.1$ - 3.7) and 4.1 (1.8 - 6.2), respectively; MDPE (\%) were $2.5(-1.1-3.7)$ and $-1.5(-4.1-0.4)$; wobble values $(\%)$ were $1.7(1.6-2.5)$ and $1.9(0.8-2.9)$, and divergence values $\left(\% \cdot \mathrm{min}^{-1}\right)$ were $-0.08(-0.11--0.02)$ and $-0.03(-0.18--0.0001)$. These results indicated that our automated system controlled AP and $\mathrm{P}_{\mathrm{LA}}$ accurately and stably without bias or trend.

\section{Blood gas analysis}

Table 1 shows the data of blood gas analysis. Despite the significant reduction in $\mathrm{CO}$, lactate remained unaltered. This result suggested that the system maintained peripheral perfusion adequately. All other blood gas parameters did not change significantly during hemodynamic control.

\section{Discussions}

We developed for the first time an automated system for administering an ultra-short-acting $\beta$-blocker, landiolol, to reduce $\mathrm{MVO}_{2}$ while controlling mean $\mathrm{AP}$ and mean $\mathrm{P}_{\mathrm{LA}}$ to preset target values in a canine $\mathrm{HF}$ model. The system controls the infusion of landiolol and dextran as well as injection of furosemide based on negative feedback control of haemodynamics. Mean AP and mean $\mathrm{P}_{\mathrm{LA}}$ reached the preset target values within $15 \mathrm{~min}$ after the system was activated. During the duration of haemodynamic control by the system, although AP decreased from baseline, mean AP and systolic AP were maintained higher than 70 and $100 \mathrm{mmHg}$, respectively. Furthermore, the system decreased $\mathrm{HR}, \mathrm{CO}, \mathrm{P}_{\mathrm{LA}}$ and $\mathrm{MVO}_{2}$ significantly, but did not affect lactate level. Therefore, our system administered landiolol and reduced $\mathrm{MVO}_{2}$ without inducing circulatory collapse under acute $\mathrm{HF}$ condition.

Comparison to other automated drug delivery systems

Recently, various automated drug delivery systems have been developed in the field of anaesthesia [2022] and for the control of volume status [23], AP [24-26] and HR [18]. Especially, the development of automated anaesthesia systems is progressing; for example, closed-loop feedback control of the bispectral index for stable control of hypnosis. Several meta-analyses have shown that automated anaesthesia delivery can be more effective than manually controlled anaesthesia by anaesthesiologists in attaining tight control with a specified range of target variables [27-29]. These systems also succeeded to reduce the doses of anaesthetics delivered and shorten the recovery time. Regarding the use of $\beta$-blockers, Jannet et al. [18] proposed a closed-loop control system for esmolol infusion. They designed the system to control the infusion rate of esmolol so as to bring the ventricular rate to preset target value in dogs with induced atrial fibrillation. Negative feedback control of esmolol infusion rate 
stably controlled the ventricular rate. However, since they did not consider other hemodynamic parameters, AP and $\mathrm{P}_{\mathrm{LA}}$ during esmolol infusion could not be predicted or controlled.

To control AP and $\mathrm{P}_{\mathrm{LA}}$ during landiolol infusion, we designed the present system by extending our previous automated drug delivery systems based on the circulatory equilibrium framework [15-17]. In this framework, circulatory equilibrium $\left(\mathrm{CO}, \mathrm{P}_{\mathrm{LA}}\right.$, and $\left.\mathrm{P}_{\mathrm{RA}}\right)$ is determined by the intersection of the FlankStarling curves and the venous return surface [30-32]. By controlling the Flank-Staring curves with dobutamine and the venous return surface with dextran and furosemide, the previous systems control CO, $P_{L A}$, and $P_{R A}$ to desired values. Based on the same framework but with different logic, the present system controls the Flank-Staring curves with landiolol and the venous return surface with dextran or furosemide to bring mean AP and mean $\mathrm{P}_{\mathrm{LA}}$ to pre-set target values (see Supplemental Material). In the canine HF model, this system achieved accurate and stable control of mean AP and mean $\mathrm{P}_{\mathrm{LA}}$, as reflected by small MDAPE for mean AP or mean $P_{L A}$. The value of MDAPE for mean AP obtained in this study was as small as those observed with our previous system [17] and systems developed by other groups [25, 26]. Therefore, the present system is the first that achieves safe and stable control of haemodynamics using a $\beta$-blocker while decreasing $\mathrm{MVO}_{2}$.

The benefit of high dose $\beta$-blockers

We designed the present system to infuse a maximum dose of landiolol in individual subject, since the benefit of $\beta$-blockers depends on the dosage. In anaesthetized dogs, Satoh et al. [33] reported that $\beta$ blockers dose-dependently reduced $\mathrm{AP}, \mathrm{HR}$ and $\mathrm{MVO}_{2}$. In patients with $\mathrm{HF}$, several studies showed that carvedilol dose-dependently improved ejection fraction and mortality rate [34, 35].

However, a high dose of $\beta$-blocker reduces cardiac pumping function, especially under HF conditions. Indeed, infusion of landiolol by our system decreased AP and CO. Although there is no clear clinical evidence of acceptable AP values under acute HF condition, previous studies recommended to maintain mean AP of over $65 \mathrm{mmHg}$ for cardiogenic shock [36] or following septic shock [37]. Therefore, we set $A P^{\star}$ as 10 to $15 \mathrm{mmHg}$ lower than baseline mean AP, but not lower than $70 \mathrm{mmHg}$. During the hemodynamic control by our system, mean AP decreased from 88 (85-89) $\mathrm{mmHg}$ at baseline to 80 (7481) $\mathrm{mmHg}$ at $60 \mathrm{~min}$, with a minimum of $70 \mathrm{mmHg}$. Although systolic AP was not a controlled variable, it was kept at not lower than $100 \mathrm{mmHg}$. Hence, our system did not induce critical hypotension. Regarding $\mathrm{CO}$, Cooper et al. [38] reported that $\mathrm{CO}$ observed after acute phase treatment in patients with acute decompensated HF was not associated with mortality or cardiovascular hospitalisation, whereas pulmonary capillary wedge pressure was a strong predictor of these events. Therefore, we designed the system to control AP and $\mathrm{P}_{\mathrm{LA}}$, but not CO. Although CO decreased from $118(95-126) \mathrm{ml} \cdot \mathrm{min}^{-1} \cdot \mathrm{kg}^{-1}$ at baseline to $89(79-97) \mathrm{ml} \cdot \mathrm{min}^{-1} \cdot \mathrm{kg}^{-1}$ at $60 \mathrm{~min}$, blood lactate level remained unaltered. This result suggests that the decrease of $\mathrm{CO}$ (approximately 25\% reduction) when using the system may not reach a critical level. Another possibility is that landiolol may reduce peripheral oxygen consumption, thereby improving the oxygen demand-supply balance. Indeed, several previous results suggest that $\beta$-blockers suppress systemic oxygen utilisation or renal oxygen consumption $[39,40]$. Thus, the present results indicate that our system does not compromise peripheral perfusion during hemodynamic control. 
Clinical application of our system

Since we invasively measured $\mathrm{CO}$ and $\mathrm{P}_{\mathrm{LA}}$ in this study, the present experimental setting may not apply to clinical practice. We previously proposed less invasive monitoring methods of $\mathrm{CO}$ and $\mathrm{P}_{\mathrm{LA}}$ using the ultrasound technique $[16,41,42]$. Use of those less invasive monitoring methods should be further explored to develop the present system for clinical application.

Limitations

The limitations of this study have to be addressed. First, the sample size was small. Since we used dogs, we reduced the sample size to the minimum necessary to achieve proof of concept. Second, all animals were anesthetized and ventilated. Anaesthesia and ventilation are known to affect haemodynamics [43]. The results of this study may be different under awake conditions. However, we consider that the negative feedback mechanism used in the present system may compensate for the variations in drug responses between anesthetized and awake states. Third, we only assessed acute $\mathrm{MVO}_{2}$ change. Further studies are needed to elucidate whether the improved myocardial energetics achieved by the present system ameliorates myocardial damage and improves long-term survival in HF subjects.

\section{Conclusions}

We have developed an automated drug delivery system that adjusts the infusion rate of landiolol to reduce $\mathrm{MVO}_{2}$ without inducing circulatory collapse. In a canine model of $\mathrm{HF}$, this system significantly reduces $\mathrm{MVO}_{2}$ indicating the potential of cardioprotection. The system controls mean AP and mean $\mathrm{P}_{\mathrm{LA}}$ accurately at the respective target values. With further development for clinical application, the system may improve cardiac energetics and reduce myocardial damage in patients with acute HF.

\section{Abbreviations}

$H F$, heart failure; $A P$, arterial pressure; $C O$, cardiac output; $P_{L A}$, left atrial pressure; $H R$, heart rate; $P_{R A}$, right atrial pressure; $R$, systemic vascular resistance; $V$, stressed blood volume; $S_{L}$, slope of Frank-Starling curve of left ventricle; $S_{R}$, slope of Frank-Starling curve of right ventricle; LVDD, left ventricular end-diastolic dimension; LVDS, left ventricular end-systolic dimension; ECG, electrocardiogram; LCX, left circumflex artery; $\mathrm{MVO}_{2}$, myocardial oxygen consumption; LVW, left ventricular weight; $\mathrm{PE}$, performance error; MDPE, median performance error; MDAPE, median absolute performance error; HR, heart rate.

\section{Declarations}

\section{Declarations}

\section{Ethics approval and consent to participate}

Animal care was performed in strict accordance with the Guiding Principles for Care and Use of Animals in the Field of Physiological Sciences, which has been approved by the Physiological Society of Japan. 
All experiments were approved by the Animal Subjects Committee at the National Cerebral and Cardiovascular Center.

\section{Consent for publication}

Not applicable

\section{Availability of data and material}

The datasets used and/or analysed during the current study are available from the corresponding author on reasonable request.

\section{Competing interests}

All authors declare that they have no competing interest.

\section{Funding}

This work was supported by Intramural Research Fund (31-6-4) for Cardiovascular Diseases of National Cerebral and Cardiovascular Center, Early-Career Scientists (19K20620) from the Japan Society for the Promotion of Science, Grant-in-Aid for Scientific Research (C) (18K12126) from the Japan Society for the Promotion of Science,.

\section{Authors' contributions}

$\mathrm{TN}$ and $\mathrm{KU}$ designed the study. TN wrote the initial draft of the manuscript. TN and KU performed the experiments. TN, KU, YH and MS contributed to analysis and interpretation of the data, and assisted in preparation of the manuscript. TN, KU, KS, TK, and MS contributed to interpretation of data, and critically reviewed the manuscript. All authors read and approved the final version of the manuscript, and agreed to be accountable for all aspects of the work in ensuring that questions related to the accuracy or integrity of any part of the work are appropriately investigated and resolved.

\section{Acknowledgements}

The authors thank the staff of the Department of Cardiovascular Dynamics, National Cerebral and Cardiovascular Center.

\section{References}

1. Aurbach GD, Spiegel AM, Gardner JD (1975) Beta-adrenergic receptors, cyclic AMP, and ion transport in the avian erythrocyte. Adv Cyclic Nucleotide Res 5:117-132 
2. Jorgensen $C R$, Wang $K$, Wang $Y$ et al (1973) Effect of propranolol on myocardial oxygen consumption and its hemodynamic correlates during upright exercise. Circulation 48:1173-1182. https://doi.org/10.1161/01.CIR.48.6.1173

3. Al-Hesayen A, Azevedo ER, Floras JS et al (2005) Selective versus nonselective beta-adrenergic receptor blockade in chronic heart failure: differential effects on myocardial energy substrate utilization. Eur J Heart Fail 7:618-623. https://doi.org/10.1016/j.ejheart.2004.04.015

4. Fung JWH, Yu CM, Yip G et al (2003) Effect of beta blockade (carvedilol or metoprolol) on activation of the renin-angiotensin-aldosterone system and natriuretic peptides in chronic heart failure. Am J Cardiol 92:406-410. https://doi.org/10.1016/s0002-9149(03)00658-1

5. Nakamura K, Murakami M, Miura D et al (2011) Beta-blockers and oxidative stress in patients with heart failure. Pharmaceuticals (Basel) 4:1088-1100. https://doi.org/10.3390/ph4081088

6. Sakanashi M, Sakanashi M, Sugahara K, Sakanashi M (2007) Effects of landiolol on mechanical and metabolic changes in rat reperfused ischaemic hearts. Clin Exp Pharmacol Physiol 34:55-60. https://doi.org/10.1111/j.1440-1681.2007.04543.x

7. Packer M, Bristow MR, Cohn JN et al (1996) The effect of carvedilol on morbidity and mortality in patients with chronic heart failure. U.S. Carvedilol Heart Failure Study Group. N Engl J Med 334:1349-1355. https://doi.org/10.1056/NEJM199605233342101

8. CIBIS-II investigators and committees (1999) The Cardiac Insufficiency Bisoprolol Study II (CIBIS-II): a randomised trial. Lancet 353:9-13

9. Butler MJ, Britton BJ, Wood WG et al (1977) Plasma catecholamine concentrations during operation. Br J Surg 64:786-790. https://doi.org/10.1002/bjs.1800641109

10. Varon J, Marik PE (2008) Perioperative hypertension management. Vasc Health Risk Manag 4:615627. https://doi.org/10.2147/vhrm.s2471

11. Sousa-Uva M, Head SJ, Milojevic M et al (2018) 2017 EACTS Guidelines on perioperative medication in adult cardiac surgery. Eur J Cardiothorac Surg 53:5-33. https://doi.org/10.1093/ejcts/ezx314

12. Prins KW, Neill JM, Tyler JO et al (2015) Effects of beta-blocker withdrawal in acute decompensated heart failure: a systematic review and meta-analysis. JACC Heart Fail 3:647-653. https://doi.org/10.1016/j.jchf.2015.03.008

13. Love JN, Howell JM, Litovitz TL, Klein-Schwartz W (2000) Acute beta blocker overdose: factors associated with the development of cardiovascular morbidity. J Toxicol Clin Toxicol 38:275-281. https://doi.org/10.1081/clt-100100932

14. Vucinić S, Joksović D, Jovanović D et al (2000) Factors influencing the degree and outcome of acute beta-blockers poisoning. Vojnosanit Pregl 57:619-623

15. Uemura K, Kamiya A, Hidaka I et al (2006) Automated drug delivery system to control systemic arterial pressure, cardiac output, and left heart filling pressure in acute decompensated heart failure. J Appl Physiol 100:1278-1286. https://doi.org/10.1152/japplphysiol.01206.2005

16. Uemura K, Kawada T, Zheng C, Sugimachi M (2016) Less invasive and inotrope-reduction approach to automated closed-loop control of hemodynamics in decompensated heart failure. IEEE Trans 
Biomed Eng 63:1699-1708. https://doi.org/10.1109/TBME.2015.2499782

17. Uemura K, Kawada T, Zheng C et al (2017) Computer-controlled closed-loop drug infusion system for automated hemodynamic resuscitation in endotoxin-induced shock. BMC Anesthesiol 17:145. https://doi.org/10.1186/s12871-017-0437-9

18. Jannett TC, Kay GN, Crossley GH (1990) Modeling and closed-loop pharmacologic control of the ventricular rate during induced atrial fibrillation in anesthetized dogs. Biomed Instrum Technol 24:445-450

19. Ngan Kee WD, Khaw KS, Ng FF, Tam YH (2013) Randomized comparison of closed-loop feedback computer-controlled with manual-controlled infusion of phenylephrine for maintaining arterial pressure during spinal anaesthesia for Caesarean delivery. Br J Anaesth 110:59-65. https://doi.org/10.1093/bja/aes339

20. LE Guen M, Liu N, Chazot T, Fischler M (2016) Closed-loop anesthesia. Minerva Anestesiol 82:573581. https://doi.org/10.1080/08998280.2017.1391036

21. Liu Y, Li M, Yang D et al (2015) Closed-loop control better than open-loop control of profofol TCI guided by BIS: a randomized, controlled, multicenter clinical trial to evaluate the CONCERT-CL closedloop system. PLoS One 10:e0123862. https://doi.org/10.1371/journal.pone.0123862

22. Luginbühl M, Bieniok C, Leibundgut $D$ et al (2006) Closed-loop control of mean arterial blood pressure during surgery with alfentanil: clinical evaluation of a novel model-based predictive controller. Anesthesiology 105:462-470. https://doi.org/10.1097/00000542-200609000-00008

23. Biegus J, Zymlinski R, Siwolowski P et al (2019) Controlled decongestion by Reprieve therapy in acute heart failure: results of the TARGET-1 and TARGET-2 studies. Eur J Heart Fail 21:1079-1087. https://doi.org/10.1002/ejhf.1533

24. Soltesz K, Sjöberg T, Jansson T et al (2018) Closed-loop regulation of arterial pressure after acute brain death. J Clin Monit Comput 32:429-437. https://doi.org/10.1007/s10877-017-0033-z

25. Ngan Kee WD, Tam YH, Khaw KS et al (2017) Closed-loop feedback computer-controlled phenylephrine for maintenance of blood pressure during spinal anesthesia for cesarean delivery: A randomized trial comparing automated boluses versus infusion. Anesth Analg 125:117-123. https://doi.org/10.1213/ANE.0000000000001974

26. Joosten A, Delaporte A, Alexander B et al (2019) Automated titration of vasopressor infusion using a closed-loop controller: in vivo feasibility study using a swine model. Anesthesiology 130:394-403. https://doi.org/10.1097/ALN.0000000000002581

27. Brogi E, Cyr S, Kazan R et al (2017) Clinical performance and safety of closed-loop systems: a systematic review and meta-analysis of randomized controlled trials. Anesth Analg 124:446-455. https://doi.org/10.1213/ANE.0000000000001372

28. Pasin L, Nardelli P, Pintaudi M et al (2017) Closed-loop delivery systems versus manually controlled administration of total iv anesthesia: a meta-analysis of randomized clinical trials. Anesth Analg 124:456-464. https://doi.org/10.1213/ANE.0000000000001394 
29. Puri GD, Mathew PJ, Biswas I et al (2016) A multicenter evaluation of a closed-loop anesthesia delivery system: a randomized controlled trial. Anesth Analg 122:106-114. https://doi.org/10.1213/ANE.0000000000000769

30. Guyton AC (1955) Determination of cardiac output by equating venous return curves with cardiac response curves. Physiol Rev 35:123-129. https://doi.org/10.1152/physrev.1955.35.1.123

31. Sunagawa K, Sagawa K, Maughan WL (1984) Ventricular interaction with the loading system. Ann Biomed Eng 12:163-189. https://doi.org/10.1007/bf02584229

32. Uemura K, Sugimachi M, Kawada T et al (2004) A novel framework of circulatory equilibrium. Am J Physiol Heart Circ Physiol 286:H2376-H2385. https://doi.org/10.1152/ajpheart.00654.2003

33. Satoh N, Suzuki J, Bessho H et al (1990) Effects of betaxolol on cardiohemodynamics and coronary circulation in anesthetized dogs: comparison with atenolol and propranolol. Jpn J Pharmacol 54:113-119. https://doi.org/10.1254/jjp.54.113

34. Bristow MR, Gilbert EM, Abraham WT et al (1996) Carvedilol produces dose-related improvements in left ventricular function and survival in subjects with chronic heart failure. MOCHA Investigators Circulation 94:2807-2816. https://doi.org/10.1161/01.cir.94.11.2807

35. Fiuzat M, Wojdyla D, Kitzman D et al (2012) Relationship of beta-blocker dose with outcomes in ambulatory heart failure patients with systolic dysfunction: results from the HF-ACTION (Heart Failure: A Controlled Trial Investigating Outcomes of Exercise Training) trial. J Am Coll Cardiol 60:208-215. https://doi.org/10.1016/j.jacc.2012.03.023

36. Vahdatpour C, Collins D, Goldberg S (2019) Cardiogenic shock. J Am Heart Assoc 8:e011991. https://doi.org/10.1161/JAHA.119.011991

37. Varpula M, Tallgren M, Saukkonen K et al (2005) Hemodynamic variables related to outcome in septic shock. Intensive Care Med 31:1066-1071. https://doi.org/10.1007/s00134-005-2688-z

38. Cooper LB, Mentz RJ, Stevens SR et al (2016) Hemodynamic predictors of heart failure morbidity and mortality: fluid or flow? J Card Fail 22:182-189. https://doi.org/10.1016/j.cardfail.2015.11.012

39. Podbregar M, Voga G (2002) Effect of selective and nonselective $\beta$-blockers on resting energy production rate and total body substrate utilization in chronic heart failure. J Card Fail 8:369-378. https://doi.org/10.1054/jcaf.2002.130238

40. Hall ME, Rocco MV, Morgan TM et al (2016) Beta-blocker use is associated with higher renal tissue oxygenation in hypertensive patients suspected of renal artery stenosis. CardioRenal Med 6:261268. https://doi.org/10.1159/000445302

41. Uemura K, Inagaki M, Zheng C et al (2015) A novel technique to predict pulmonary capillary wedge pressure utilizing central venous pressure and tissue Doppler tricuspid/mitral annular velocities. Heart Vessels 30:516-526. https://doi.org/10.1007/s00380-014-0525-4

42. Uemura K, Kawada T, Inagaki M, Sugimachi M (2013) A minimally invasive monitoring system of cardiac output using aortic flow velocity and peripheral arterial pressure profile. Anesth Analg 116:1006-1017. https://doi.org/10.1213/ANE.0b013e31828a75bd 
43. Beam DM, Neto-Neves EM, Stubblefield WB et al (2015) Comparison of isoflurane and a-chloralose in an anesthetized swine model of acute pulmonary embolism producing right ventricular dysfunction. Comp Med 65:54-61

\section{Tables}

Table 1. Results of blood gas analysis of five dogs.

\begin{tabular}{|c|c|c|c|c|c|c|c|}
\hline \multirow[b]{2}{*}{$\mathrm{pH}$} & \multicolumn{2}{|c|}{$0 \mathrm{~min}$} & \multicolumn{2}{|c|}{$30 \mathrm{~min}$} & \multicolumn{2}{|c|}{$60 \mathrm{~min}$} & \multirow{2}{*}{$\begin{array}{l}\text { p-value } \\
0.37\end{array}$} \\
\hline & 7.46 & $(7.45-7.46)$ & 7.46 & $(7.45-7.46)$ & 7.45 & $(7.44-7.46)$ & \\
\hline $\mathrm{Na}^{+}\left(\mathrm{mEq} \cdot \mathrm{l}^{-1}\right)$ & 143 & $(141-145)$ & 144 & $(143-144)$ & 145 & $(141-145)$ & 0.65 \\
\hline $\mathrm{K}^{+}\left(\mathrm{mEq} \cdot \mathrm{I}^{-1}\right)$ & 3.3 & $(3.2-3.3)$ & 3.1 & $(3.1-3.3)$ & 3.1 & $(3.0-3.4)$ & 0.59 \\
\hline $\mathrm{Cl}^{-}\left(\mathrm{mEq} \cdot \mathrm{I}^{-1}\right)$ & 118 & $(117-119)$ & 119 & $(118-120)$ & 118 & $(118-120)$ & 0.06 \\
\hline $\mathrm{Ca}^{2+}\left(\mathrm{mEq} \cdot \mathrm{l}^{-1}\right)$ & 2.32 & $(2.19-2.43)$ & 2.26 & $(2.25-2.3)$ & 2.3 & $(2.16-2.32)$ & 0.95 \\
\hline Lactate $\left(\mathrm{mg} \cdot \mathrm{dl}^{-1}\right)$ & 11 & $(8-16)$ & 15 & $(10-16)$ & 13 & $(8-15)$ & 0.53 \\
\hline $\mathrm{HCO}_{3}^{-}\left(\left.\mathrm{mmol} \cdot\right|^{-1}\right)$ & 18.7 & $(18.3-18.8)$ & 18.6 & $(18.6-18.6)$ & 18.5 & $(18.3-18.7)$ & 0.55 \\
\hline $\mathrm{BE}\left(\mathrm{mmol} \cdot \mathrm{l}^{-1}\right)$ & -4.3 & $(-4.7--2.8)$ & -4.3 & $(-4.4--3.7)$ & -4.2 & $(-4.8--3.8)$ & 0.31 \\
\hline $\mathrm{PaO}_{2}(\mathrm{mmHg})$ & 103 & $(93-132)$ & 73 & $(72-124)$ & 110 & $(77-120)$ & 0.45 \\
\hline $\mathrm{PaCO}_{2}(\mathrm{mmHg})$ & 27.6 & $(26.2-29.1)$ & 26.9 & $(26.5-28)$ & 27.9 & $(26.9-28.1)$ & 0.95 \\
\hline
\end{tabular}

Data are expressed as median ( 25 - 75 percentiles). 0 min, 30 min, and 60 min represent the time after activating the automated drug delivery system. $\mathrm{BE}$, base excess; $\mathrm{PaO}_{2}$, partial pressure of arterial oxygen; $\mathrm{PaCO}_{2}$, partial pressure of arterial carbon dioxide.

\section{Figures}

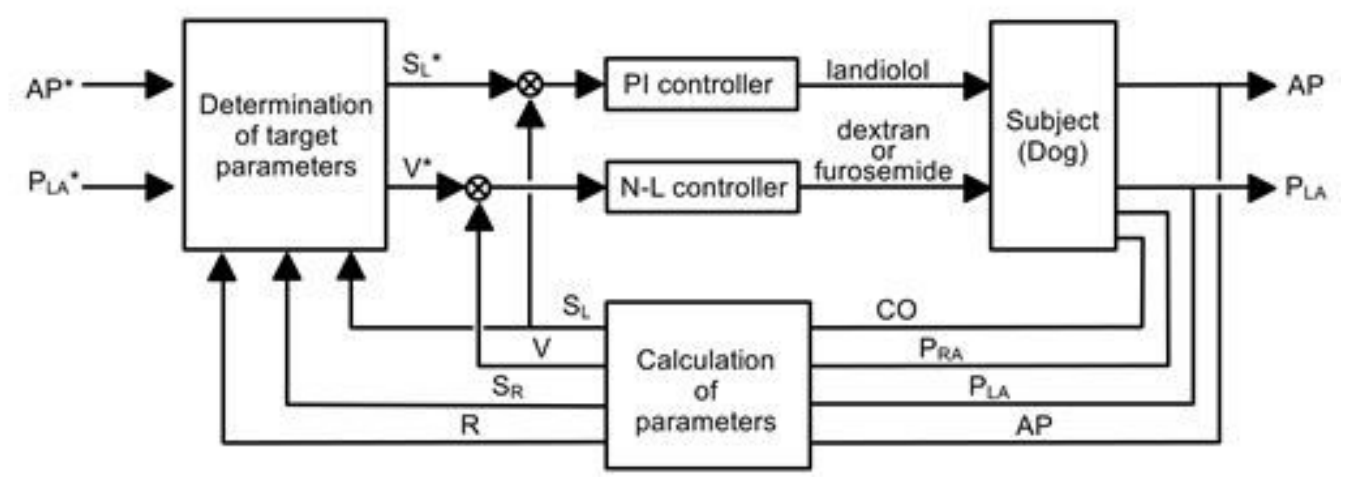


Figure 1

Schematic representation of the automated drug delivery system to control arterial pressure (AP) and left atrial pressure (PLA). From measured AP, PLA, right atrial pressure (PRA) and cardiac output (CO), the system calculates hemodynamic parameters comprising SL (slope of Frank-Starling curve for left ventricle), SR (slope of Frank-Starling curve for right ventricle), stressed blood volume $(V)$ and systemic vascular resistance $(R)$. From $S R, R$, target $A P\left(A^{\star}\right)$ and target $P L A\left(P L A^{*}\right)$, the system determines target $S L\left(S L^{*}\right)$ and $V\left(V^{*}\right)$. The infusion rate of landiolol is controlled by a proportional-integral $(\mathrm{PI})$ controller to minimise the difference between SL* and SL. The infusion rate of dextran and injection of furosemide are controlled by a nonlinear $(\mathrm{N}-\mathrm{L})$ controller to minimise the difference between $\mathrm{V}$ * and $\mathrm{V}$. By controlling $\mathrm{SL}$ and $\mathrm{V}, \mathrm{AP}$ and PLA reach preset target values.
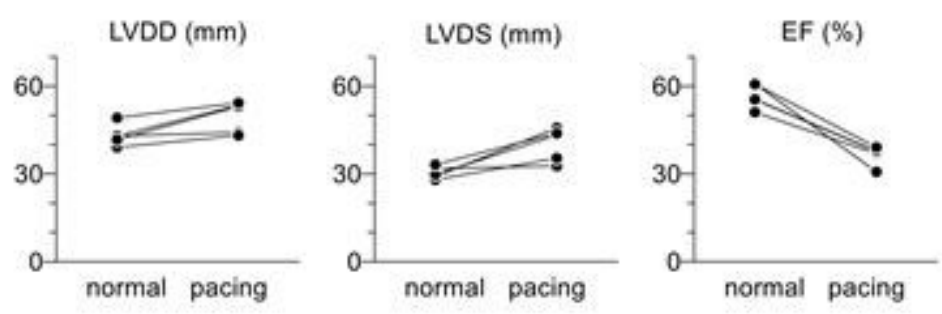

\section{Figure 2}

Echocardiographic variables of cardiac function measured before (normal) and after three weeks of rapid cardiac pacing to induce heart failure. LVDD, left ventricular end-diastolic dimension; LVDS, left ventricular end-systolic dimension; EF, ejection fraction.

A
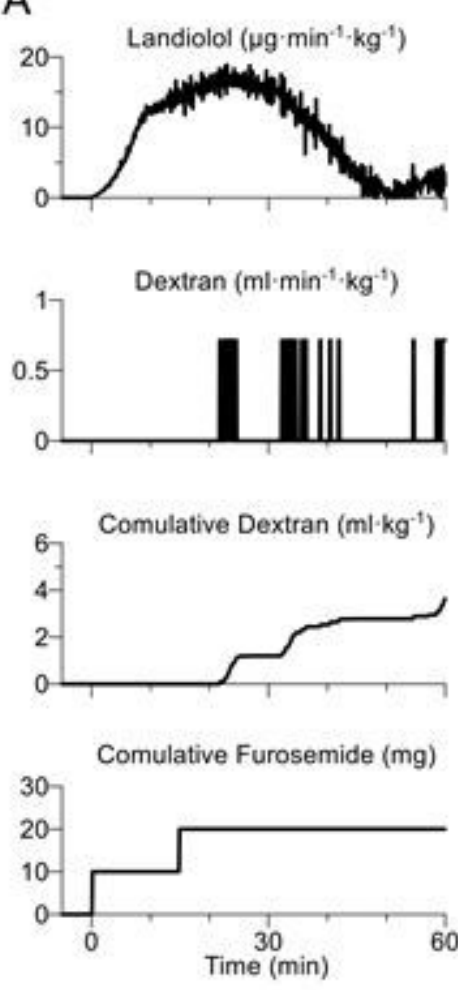

B

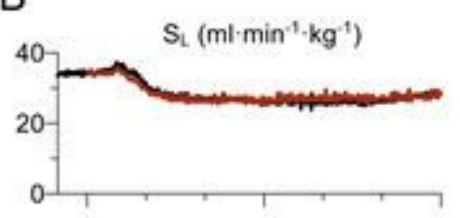

$\mathrm{V}\left(\mathrm{ml} \cdot \mathrm{kg}^{-1}\right)$
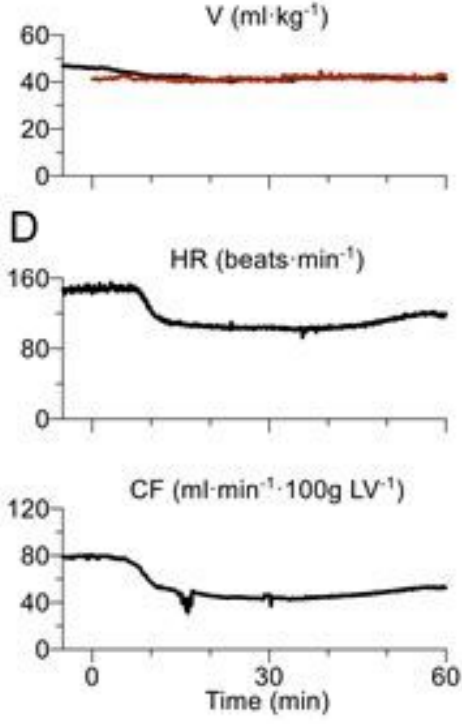

C
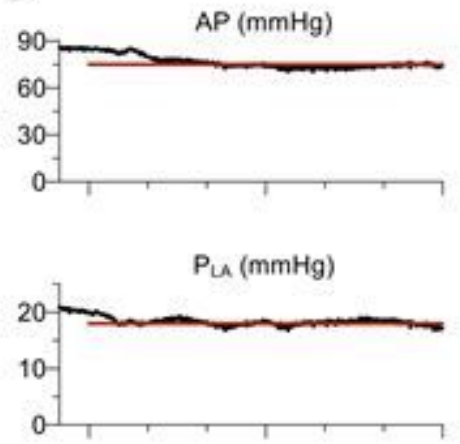

$\mathrm{E}$

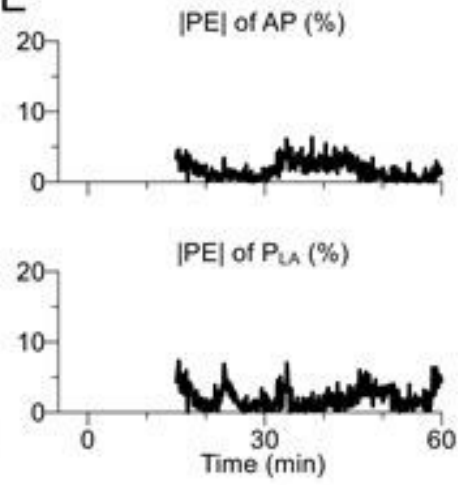




\section{Figure 3}

Representative time series data of one dog during hemodynamic control by the automated drug delivery system. (A) Infusion rates of landiolol and dextran, and cumulative doses of dextran and furosemide; (B) slope of Frank-Starling curve for left ventricle (SL) and stressed blood volume (V); (C) mean arterial pressure (AP) and mean left atrial pressure (PLA); (D) heart rate (HR) and coronary flow (CF); (E) absolute performance error (|PE|) for AP and PLA. Black and red lines indicate measured and target values, respectively.
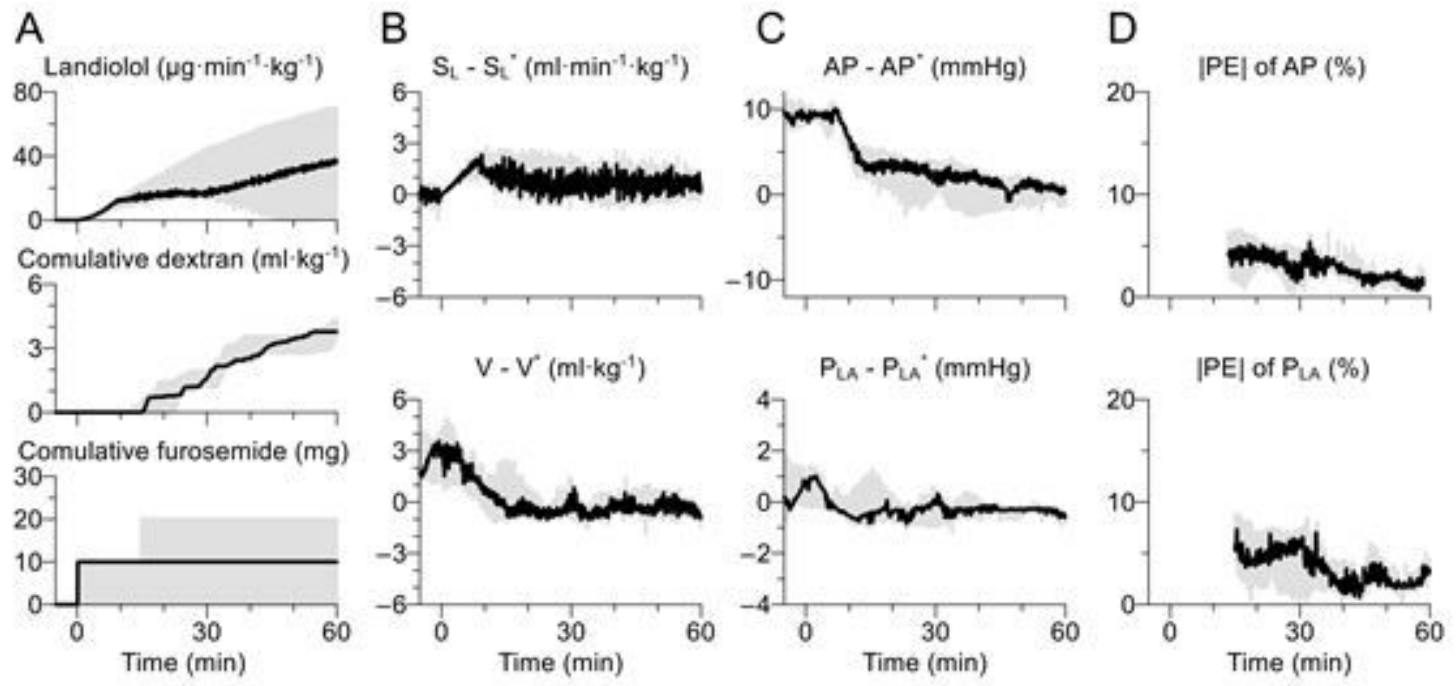

Figure 4

Summarised time series data of five dogs during hemodynamic control by the automated drug delivery system. Data are expressed as median (solid line) and interquartile range (grey area). (A) Infusion rates of landiolol and dextran, and cumulative doses of dextran and furosemide; (B) difference between measured and target values of slope of Frank-Starling curve for left ventricle (SL) and stressed blood volume (V); (C) difference between measured and target values of mean arterial pressure (AP) and mean left atrial pressure (PLA); (D) absolute performance error (|PE|) for AP and PLA. 

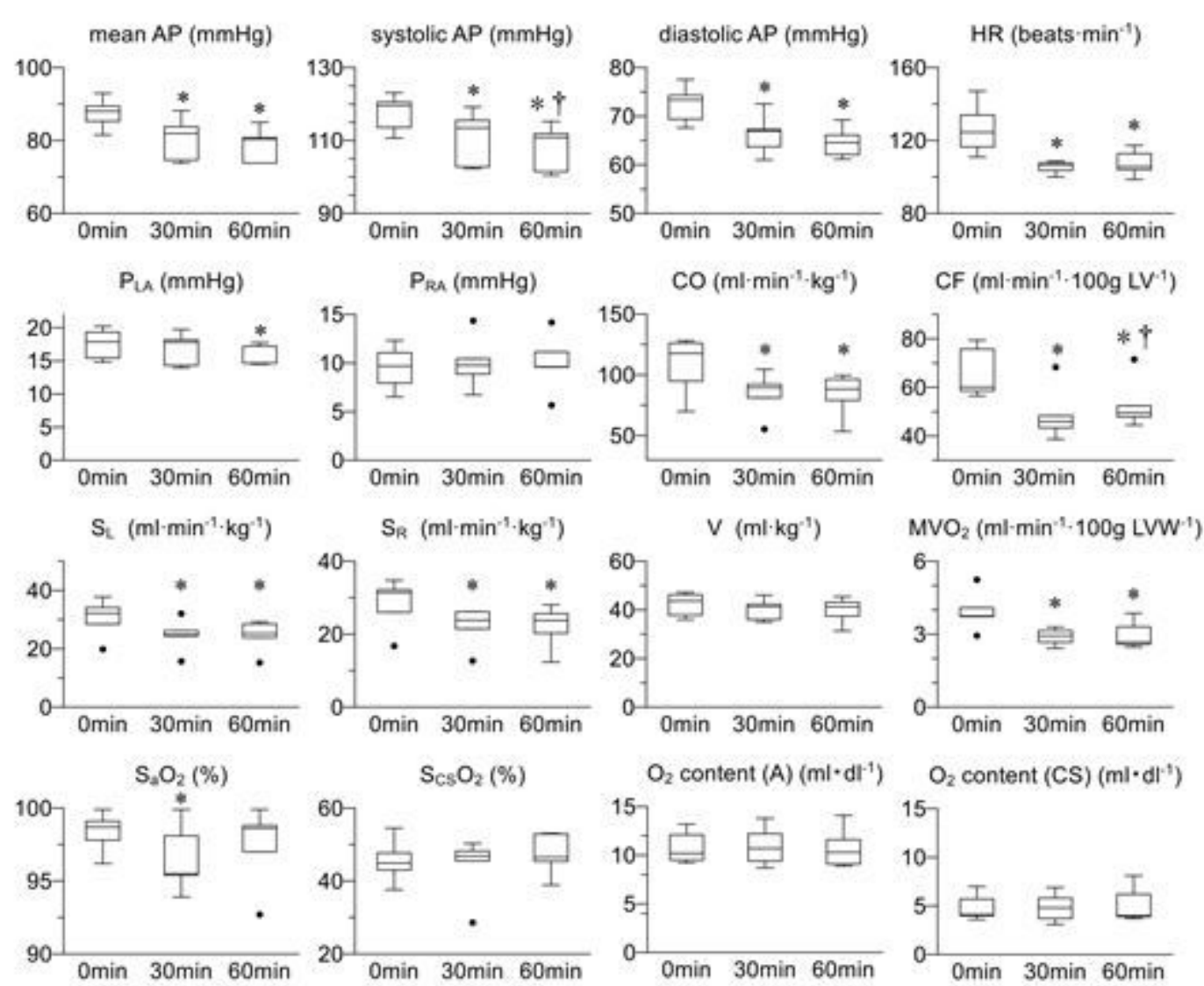

\section{Figure 5}

Summarised hemodynamic and energetics data of five dogs obtained at $0 \mathrm{~min}, 30 \mathrm{~min}$, and $60 \mathrm{~min}$ after the system was activated. Boxes represent median and interquartile range. Whiskers represent minimum and maximum values. Outliers are represented as circles. AP, arterial pressure; PLA, left atrial pressure; PRA, right atrial pressure; $\mathrm{HR}$, heart rate; $\mathrm{CO}$, cardiac output; $\mathrm{CF}$, coronary flow; $\mathrm{SL}$, slope of Frank-Starling curve for left ventricle; SR, slope of Frank-Starling curve for right ventricle; V, stressed blood volume; $\mathrm{MVO}$ 2, cardiac oxygen consumption; SaO2, arterial oxygen saturation; ScsO2, oxygen saturation of coronary sinus (CS); A, arterial blood. ${ }^{\star} p<0.05$ vs. 0 min, $\uparrow p<0.05$ vs. 30 min. 

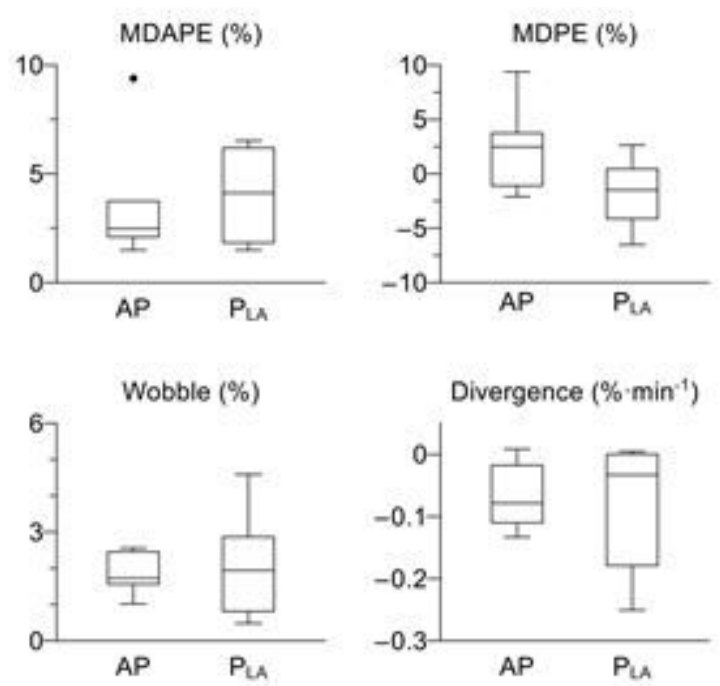

Figure 6

Performance errors of hemodynamic control by the automated drug delivery system. AP, arterial pressure; PLA, left atrial pressure; MDAPE, median absolute performance error; MDPE, median performance error. Boxes represent median and interquartile range. Whiskers represent minimum and maximum values. Outliers are represented as circles.

\section{Supplementary Files}

This is a list of supplementary files associated with this preprint. Click to download.

- landiololsupplement20200730.docx 